\title{
DISENSOS TEÓRICOS
}

Mauro Barberis *

El tema de los disensos teóricos, en algún sentido, no pertenece a ninguna de las tres categorías de temas sobre los cuales debería ocuparse esta sección: 1) temas que han sido discutidos, pero que ya no se discuten; 2) temas que todavía se discuten, aunque no lo suficiente, y 3 ) temas que no han sido nunca discutidos, pero que deberían discutirse. Por otro lado, en cambio, el tema mismo pertenece a las tres categorías. Circunstancia ésta lo suficientemente curiosa que, por tanto, invita a adentrarse en él.

1. Se trata, sobre todo, de un tema que no se discute más, o sobre el cual se discute cada vez menos. Al menos en comparación con los tiempos de oro de la filosofía analítica aplicada al derecho. Existió un período, entre los años cincuenta y sesenta del siglo XX, en el cual se dedicaba un espacio (casi) excesivo a las cuestiones epistemológicas, metodológicas, meta-teóricas y meta-éticas. Hoy, en cambio, se prefieren temas "sustanciales" -no obstante el hecho de que la diferencia entre forma y sustancia sea hoy poco más que mera metáfora- o, mejor dicho, directa o indirectamente temas "normativos". Así, el problema meta-teórico de los disensos teóricos ha sobrevivido en las discusiones de metodología de la ciencia jurídica (y reflorecido poco tiempo atrás), con la victoria del positivismo jurídico en la batalla contra el antipositivismo de Dworkin. Nos ocuparemos de esto a continuación.

2. Se trata, por tanto, de un tema que se ha vuelto a discutir recientemente, luego de un período dedicado a las teorías del sistema, del

* Profesor de Filosofía del derecho de la Facultad de Derecho. Universidad de Trieste, Italia. 
razonamiento y la interpretación jurídica. Un tema que se ha hecho casi explícito en la discusión de filosofía política y al menos implícito en la discusión de filosofía jurídica. Veamos tres ejemplos.

Primer ejemplo. Uno de los textos más importantes en el debate sobre el tema de la democracia deliberativa, cuyos autores son Amy Gutman y Dennis Thompson, se titula precisamente Democracy and Disagreement (1994). La idea central es que "cuando los ciudadanos o sus representantes desacuerdan moralmente, deberían continuar razonando conjuntamente para alcanzar decisiones mutuamente aceptables". Aquí se admite sin más que en política el desacuerdo moral es de hecho insuperable, y que esta imposibilidad debe servir como punto de partida para re-pensar de manera realista la política. No obstante, toda la discusión sobre el value pluralism y sobre la inconmensurabilidad de los valores nos sugiere o indica quizás algo más: el disenso moral o normativo no constituye un rasgo patológico de la discusión ética, sino más bien fisiológico.

Segundo ejemplo. El único texto orgánico de Ronald Dworkin en el ámbito de la filosofía jurídica, Law's Empire (1986), afirma que el principal límite de la teoría jurídica iuspositivista radicaría en no dar cuenta de los "theorical disagreements about law" que se suscitan entre los juristas. El positivismo jurídico reduciría estos desacuerdos a desacuerdos de hecho, o "semánticos"; la teoría del mismo Dworkin, en cambio, tendría el mérito de tratarlos no sólo como desacuerdos sobre el derecho -ya sea sobre el quid ius, o sobre el quid iuris, entre sí siempre confundidos por Dworkin- sino también como desacuerdos interpretativos, argumentativos, justificativos. Como suele suceder, Dworkin tiene el mérito de indicar el problema, pero hace poco o nada por resolverlo. Su solución -el recurso a la interpretación como búsqueda de la única respuesta correcta- consiste en aclarar obscurum per obscurius.

Tercer ejemplo. Siempre como by-product de la discusión entre Dworkin y los iuspositivistas se ha abierto, dentro del campo iuspositivista mismo, una discusión sobre el status (semántico, lógico, epistemológico) de la teoría del derecho misma. Es quizás aquí, precisamente, como extensión de esta 
discusión, que se deberían discutir los desacuerdos teóricos sobre el derecho. No sólo de los desacuerdos morales de los que hablan los filósofos políticos, y ni siquiera de los desacuerdos interpretativos de los que habla Dworkin, sino también de los desacuerdos teóricos que, aunque distintos a los anteriores, se conectan con ellos.

3. Se trata, en definitiva, de un tema que en cierto sentido jamás ha formado parte de ninguna agenda de discusión y que, no obstante, se encuentra implícito en todas las agendas y resulta preliminar con respecto a cualquier discusión teórica. Preliminar incluso, y sobre todo, a las discusiones que tienen lugar en una revista que se llama Discusiones. ¿Cuál es el status del desacuerdo teórico?

A fin de indicar el punto desde donde podría partir una discusión que supera mis capacidades, me limitaré a las siguientes indicaciones. En la edad de oro de la filosofía analítica Charles Stevenson había distinguido entre dos tipos de desacuerdo -desacuerdos sobre las creencias y desacuerdos sobre las actitudes- mostrando que entre dos sujetos puede haber pleno acuerdo sobre las creencias relativas a ciertos hechos o actos y, no obstante, desacuerdo sobre las actitudes.

Hoy en día se impondría distinguir al menos cuatro tipos "puros" de disensos "teóricos" que, en realidad, se entrecruzan estrechamente en toda discusión.

En primer lugar, existen desacuerdos empírico-cognoscitivos: existen, entre los teóricos, diversos modos de reconstruir los datos provistos por las ciencias sociales o por la experiencia directa de los juristas. Este aspecto de la teoría del derecho, por otra parte, no puede subestimarse (como todavía tienden a hacer los herederos del realismo jurídico). Los datos empíricos son ciertamente importantes para la construcción de teorías, pero no son jamás decisivos ya que también las teorías jurídicas están sub-determinadas por la experiencia.

En segundo lugar existen desacuerdos ético-normativos: por ejemplo, buena parte del desacuerdo entre iuspositivistas y iusnaturalistas no depende 
tanto del diferente valor que unos y otros atribuyen a ciertos hechos, sino más bien del diferente peso que les atribuyen a las valoraciones y el conocimiento como ingredientes de la construcción de una teoría del derecho. También este aspecto de la teoría del derecho, por otra parte, no debe subestimarse. Las valoraciones éticas, que intervienen tanto al principio como durante la construcción de las teorías, no hacen más que sub-determinarlas. Diversas teorías pueden surgir de (o ser generadas por) una y la misma valoración ética, y diversas valoraciones éticas pueden generar una y la misma teoría.

En tercer lugar, existen desacuerdos analítico-cognoscitivos, quizás más profundos e importantes que los desacuerdos ético-normativos. En última instancia todo depende de las definiciones de las palabras. Definiciones en las cuales se manifiesta, consciente o inconscientemente, aquello que el Wittgenstein de las Bemerkungen über die Grundlagen der Mathematik(1937-1938) llamaba nuestra "profunda necesidad de convención".

Por último, existen los desacuerdos metafísicos: es decir, los desacuerdos típicos de las filosofías "sintéticas", o no-analíticas, pero también del discurso ordinario y sentido común. Estos desacuerdos parecen insuperables, quizás, sólo porque ignoran, conscientemente o no, todas o al menos algunas de las distinciones precedentes. En particular, la distinción entre empírico y analítico, y entre cognoscitivo y normativo.

Al menos a partir del Wittgenstein de Über Gewißheit (póstumo, 1969) y del Willard Quine de Two Dogmas of Empiricism (1951) resulta normal configurar las teorías científicas no como sistemas de proposiciones fundadas sobre la experiencia sino como redes de proposiciones más o menos resistentes a la falsación empírica. En orden a clarificar el tema de los desacuerdos entre teorías filosóficas con respecto a temas moral, política o jurídicamente relevantes, se impone por cierto agregar a este cuadro las valoraciones (normativas). Sin embargo, no resulta para nada obvio que las valoraciones, en los disensos teóricos, jueguen un rol más importante que el que juegan las definiciones (implícitas o explícitas). Estas últimas, por el contrario, parecen constituir el núcleo profundo de cualquier teoría, sea ésta científica, filosófica, y también filosófico-jurídica. 